\title{
Construction of Student Representasi on Three-Dimensional Word Problem
}

Anwar Muttaqien

SMAN 2 Sampit; STKIP Muhammadiyah Sampit, Indonesia

\section{ARTICLE'S \\ INFORMATION}

Article history:

Received: Nov-07-2019

Accepted: Nov-22-2019

\section{Keywords:}

Pictorial representation, schematic

representation, word problem

Corresponding address:

\section{ABSTRACT}

Many students have difficulty solving the word geometry problem because it requires representation. This study analyzes the construction of representation of class XII students in solving three dimensional word problem. Research with descriptive methods to determine the representation construction that students use when given the task of solving three dimensional word problem. The results showed two constructs of representation, namely: pictorial representation and schematic representation. Students who construct pictorial representations produce correct answers while students who construct schematic representations produce correct answers in solving three-dimensional word problems.

Anwar Muttaqien

Anwarmuttaqien1503@gmail.com

\section{INTRODUCTION}

Real-world problems requiring solutions, usually not in form of equations, but rather as sentences that must be represented [1]. Verbal descriptions of real situations, where a question is asked, and an answer is obtained by applying mathematical operations called a word problem.

In the 2013 curriculum, one of the contents of Class XII high school content: Describe and present the distance point to point, point to line and point to the plane in space. This curriculum, emphasizes the ability of students to make 'representations' in solving word problems.

Solving word problems involves more than basic computing skills. An effective word problem solver can understand word problems by demonstrating its ability to explain word problems in their own words. Understanding word problems requires the interaction of linguistic knowledge and familiarity with real-world situations. Understanding is an important aspect of solving word problems.

Some researchers [2] [3] [4] [5] state that students often have difficulty in solving word problems. Experts [6] [7] [8] also revealed the difficulties experienced by students due to reading comprehension and not understanding word problems. Other experts [9] [10] state that difficulties also occur in mathematical language and situation models. This shows that solving the word problem becomes an important study.

At the time of solving the problem needed understanding [8], and to understand the problem needed representation [11] to succeed in solving the word problem. Thus it is necessary to examine the use of representation by students. The question is whether students use representations, and what types of representations students use in solving three-dimensional word problems. This study aims to determine the representation used by high school students. The expected benefit is for the teacher's knowledge in teaching word problems in mathematics 
classrooms and also for students to describe the type of representation that is useful for successful mathematical problem-solving.

Students use representations to support their understanding when solving mathematical problems or learning new mathematical concepts [12]. [13] stated that there are two representation systems, namely internal and external. The internal system of representation is created in one's mind and is used to establish mathematical meaning. External systems of representation include conventional representations that are usually symbolic, for example, mathematical equations, algebraic expressions, graphs, geometric drawings, and number lines.

Bruner [14], found three types of external representations, namely: active, iconic, and symbolic. The following five types of representations: (a) real-life experiences, (b) manipulative models, (c) pictures or diagrams, (d) spoken words, and (e) ) written symbol. This category can be considered an extension of the three types of representations of Bruner. Real-life experiences and manipulative models are enactive representations, drawings and diagrams are iconic representations, and written words and symbols are symbolic representations.

Research on types of representation in solving word problems is conducted by [15]; [16]; [17] found two types of representations used in mathematical word problem solving are: (a) pictorial representations, visual displays of objects including details that are not relevant to the solution, (b) schematic representations, displaying relevant spatial relations for solving word mathematical problem.

Sandra M. Crespo; Andreas O. Kyriakides [16],found two types of image representations used in solving word problems: (a) pictographic images, realistic images that tend to be detailed of objects mentioned in the word problem, (b) iconic images, not realistic; tend to use simple forms for the representation of objects that are needed in solving word problems.

\section{METHODELOGY}

This research uses descriptive method by describing the type of representation used by the 6 students of class XII of SMAN 2 Sampit at the beginning of the 2019/2020 school year. Students do not receive special instructions before working on three-dimensional word problems. Word problems used are as follows:

Do whatever will help you to solve the problem below!

Ahmad's room is a beam with a length of 5 meters, a width of 5 meters and a height of 3 meters. On the ceiling of the room, some lights are located right in the center of the ceiling. In one area of the room, a switch is located right in the middle of the wall. Calculate the distance of the switch to the lamp.

\section{RESULT AND DISCUSSION}

Representations of student construction can be pictorial representations of images of objects that refer to the context of the word problem, or schematic representations of simple drawings that describe the problem. Verbal representation is reformulating statements in personal language style. Arithmetic representation is the calculation of the point to point distance in the building space.

Representations of student construction can be pictorial representations of images of objects that refer to the context of the word problem, or schematic representations of simple drawings that describe the problem. Verbal representation is reformulating statements in personal 
language style. Arithmetic representation is the calculation of the point to point distance in the building space.

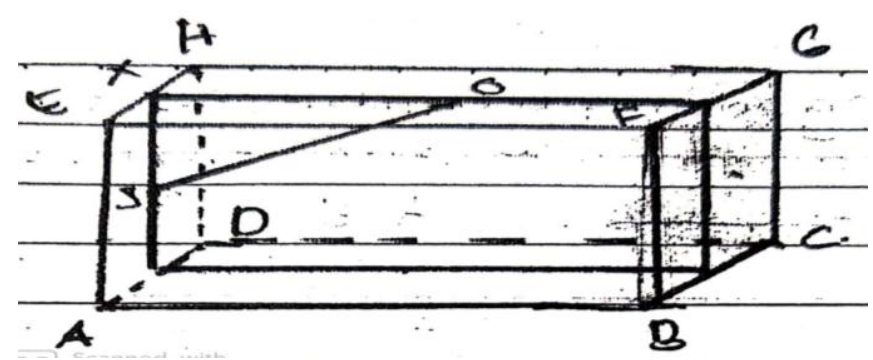

Figure 1. Construction of Pictorial Representations

The image created is a concrete image of the problem. Researchers ( [15]; [18]; [19] [16]; [20]; [21] stated that pictorial representations are pictures of objects or people only on certain statements referred to in word problems. This shows that the subject relies on concrete images in understanding the word problem. Van Garderen \& Montague (2003) states that students who lack understanding word problems rely more on concrete images that are ineffective and inefficient for solutions.

A total of 27 students used schematic representation with 100\% correct answers. Students used schematic representation that previously made verbal representations. After making the representation, it is continued by writing a solution in the form of arithmetic representation.

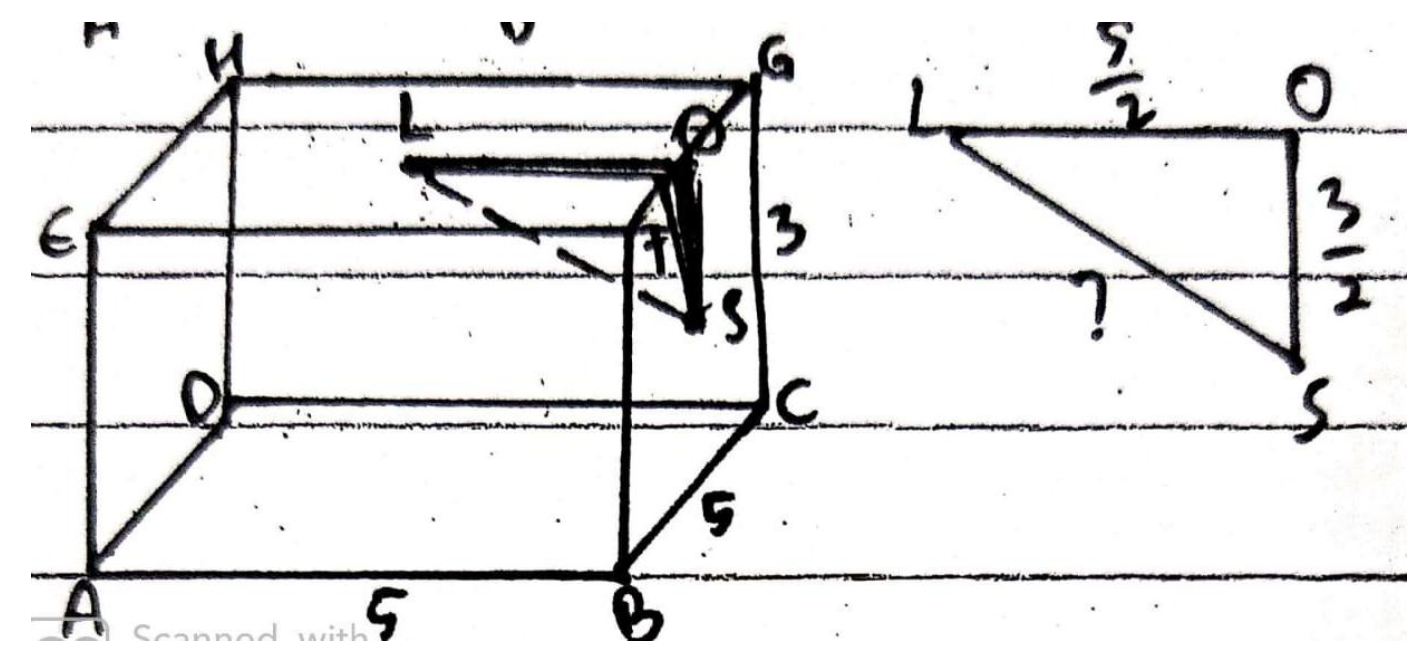

Figure 2. Construction of schematic representation.

Schematic representation is found in students who use schemes in the process of solving three-dimensional word problems. The process of schematic representation is done by identifying and transforming statements into other different forms, making relationships and making simple two-dimensional drawings in the form of right triangles and doing calculations based on simple shapes of these right triangles. 
Students create a scheme that connects three-dimensional shapes with two dimensions. Researchers ( [15]; [18]; [19]; [16]; [20]; [21] stated that schematic representation is to make schemes that connect between representations into simple forms.

\section{CONCLUSIONS AND SUGGESTIONS}

One of the objectives of this research is to describe the construction of student representation in solving three-dimensional word problems. A total of 3 students using pictorial representations, the results of the three students' answers were wrong. A total of 27 students used a schematic representation that links three-dimensional and two-dimensional images to produce simple representations. The result is that all students who use schematic representation are able to solve three-dimensional word problems correctly. Thus it is recommended that teachers provide opportunities for students to make schematic representations so that students' answers are correct

\section{REFERENCES}

[1] D. D. Cummins, "Children's Interpretations of Arithmetic Word Problems," Cognition and Instruction, vol. 8, no. 3, pp. 261-289, 1991.

[2] H. Lee Swanson; Catherine Lussier; Michael Orosco, "Effects of Cognitive Strategy Intervention on Word Problem Solving and Working Memory in Children with Math Disabilities," Society for Research on Educational Effectiveness, pp. 1-10, 2011.

[3] K. K. J. Yeo, "Secondary Students' Difficulties in Solving Non-Routine Problems," NanyangTecnological University, Singapore, 2010.

[4] R. I. Charles, "Solving Word Problems. Developing Students'Quantitative Reasoning Abilities. California: Pearson," San Jose State University, San Jose, 2009.

[5] Azlina Ahmad; Siti Salwa Salim; Roziati Zainuddin, "Supporting Mathematical Communication in Word Problem Solving Through a Cognitive Tool," in International Conference on EDUCATION and EDUCATIONAL TECHNOLOGY, Italy, 2008.

[6] B. S. Wright, "Ways To Decode, Decipher, And Apply Skills To Word Problems," St. John Fisher Colege, 2010.

[7] JaLena J. Clement; Wolbach N.E, "Does Decoding Increase Word Problem Solving Skills?," Department of Mathematics University of Nebraska, Lincoln, 2008.

[8] D. v. Garderen, "Focus On Inclusion Reciprocal Teaching As A Comprehension Strategy For Understanding Mathematical Word Problems.," State University of New York at New paltz, New York, 2004.

[9] A. Mattarella-Micke; L.S. Beilock , "Situating math word problems: The story matters," Psychonomic Bulletin \& Review, vol. 17, no. 1, pp. 106-111, 2010.

[10] D. Kotsopoulos, "Matthematics Discourse: It's like hearing a foreign language," Mathematics Teacher, vol. 101, no. 4, pp. 301-305, 2007.

[11] S. J. Pape, "Middle school childrens' problem-solving behavior: A Cognitive analysis from a 
reading comprehension perspective," Journal for Research in Mathematics Education, vol. 35, no. 3, pp. 187-219., 2004.

[12] Gwenane M.Salkind; Margaret Hjalmarson, "Mathematical Representations," EDCI 857 Preparation and Professional Development of Mathematics Teachers, Spring, 2007.

[13] G. A. Goldin, "Representation in mathematical learning and problem solving," in Handbook of international research in mathematics education, Lawrence Erlbaum Associates, 2002, pp. 197-218.

[14] J. Bruner, "Towards a theory of instruction," Harvard University Press, Cambridge, 1966.

[15] Mary Hegarty; Maria Kozhevnikov, "Types of Visual-Spatial Representations and Mathematical Problem Solving," Journal of Educational Psychology, vol. 91, no. 4, pp. 684689, 1999.

[16] Sandra M. Crespo; Andreas O. Kyriakides, "To Draw or Not to Draw: Exploring Children's Drawings for Solving Mathematics Problems," Teaching Children Mathematics, vol. 14, no. 2, pp. 118-125, 2007.

[17] Fany M. Gonzales Barrios; Enrique Castro Martinez, "Diagrams Produced by Secondary Students in Multiplicative Comparison Word Problems," Journal of Mathematics and System Science, vol. 4, no. 14, pp. 83-92, 2014.

[18] Delinda van Garderen; Marjorie Montague, "Visual-Spatial Representation, Mathematical Problem Solving and Students of Varying Abilities," Learning Disabilities Research \& Practice, vol. 18, no. 4, p. 246-254, 2003.

[19] D. V. Garderen, "Spatial Visualization, Visual Imagery, and Mathematical Problem Solving of Students with Varying Abilities," Journal of Learning Disabilities, vol. 39, no. 6, p. $496-$ 506, 2006.

[20] Anton J.H. Boonen; Floryt van Wesel; JellyJolles; Manno van der Schoot, "Boonen, J.What underlies successful word problem solving? A jalur analysis in sixth grade students," Contemporary Educational Psychology, vol. 38, no. 2013, p. 271-279, 2013.

[21] F. M. Barrios and E. C. Martinez, "Diagrams Produced by Secondary Students in Multiplicative Comparison Word Problems," Journal of Mathematics and System Science, vol. 4, no. 2014, pp. 83-92, 2014.

[22] D. D. Cummins, "Children's Interpretations of Arithmetic Word Problems," vol. 3, pp. $261-$ 289, 1991.

\section{BIOGRAPHY}

Anwar Muttaqien, Pendidikan dimulai dari S1 Pendidikan matematika ditempuh di Universitas Palangkaraya dan S2, S3 di Pascasarjana Universitas Negeri Malang. Mengajar di SMAN 2 Sampit dan STKIP Muhammadiyah Sampit. HP 081352849939, Email: anwarmuttaqien1503@gmail.com. 